\title{
A study of severity of intention of suicide in various psychiatric diagnoses
}

\author{
Pradhan SN 1 , Adhikary SR ${ }^{2}$ \\ ${ }^{1}$ Assistant Professor, ${ }^{2}$ Lecturer of Department of Psychiatry, Kathmandu Medical College Teaching Hospital
}

\begin{abstract}
Background: Suicidal intent has been described as the seriousness or intensity of the patient's wish to terminate his or her life. Suicide has become an important public health issue throughout the world. It is important to evaluate the intentions of suicide attempts and various psychiatric diagnostic perspectives to understand the multiple dimensions of suicide.

Aims: The aim of the work was to study the severity of suicidal intention among suicide attempters in different psychiatric diagnoses and different mode of attempted suicide.

Materials and methods: This study was carried out in the patients, who attempted suicide, by various modes, who were admitted in the wards of KMCTH during $1^{\text {st }}$ January 2007 to $30^{\text {th }}$ December 2007. Suicide Intent Scale (SIS) was used in all the cases that had attempted suicide.

Results: Total numbers of patients was 43. Mean SIS was 13.88. The results have shown that majority of cases were female $69.8 \%(n=30)$ and male were $30.2 \%(n=13)$. The commonest mode of suicide was poisoning $83.7 \%(n=36)$ in which moderate suicide intent was $58.3 \%(n=21)$; mild suicide intent $33.3 \%(n=12)$ and severe suicide intent $8.3 \%(n=3)$. Pesticide (organophosphorus) ingestion was the commonest mode of suicide $44.4 \%(n=16)$, followed by pharmacological drugs $33.3 \%(n=12)$. The commonest psychiatric diagnosis was depressive disorders $62.9 \%(n=27)$, in which moderate suicide intent was found to be maximum $70.4 \%(n=19)$ followed by mild suicide intent $14.8 \%(n=4)$ and severe suicide intent $14.8 \%(n=4)$.

Conclusion: The increasing problem of pesticide poisoning and drug overdose demands strict legal scrutiny in the availability of common means of attempting suicide.
\end{abstract}

Key words: Attempted suicide, Suicide intent scale, Organophosphorous poisoning, psychiatric diagnoses

Quicidal has been described as the seriousness or $\checkmark$ intensity of the patient's wished to terminate his or her life ${ }^{1}$. Increased suicide risk after attempted suicide involves the factors like male gender, advancing age, psychiatric disorder, and previous psychiatric treatment, long term use of hypnotics, poor physical health, living alone ${ }^{2,3}$, and 4 . Suicidal acts with non fatal outcome are labeled by WHO as either suicide attempts, attempted suicides, parasuicides or acts of deliberate self-harm ${ }^{5}$.

\section{Aim}

The aim of the work was to study the severity of suicidal intention among suicide attempters in different psychiatric diagnosis.

\section{Materials and methods}

This study was carried out in the patients, who attempted suicide, by various modes, who were admitted in the wards of KMCTH during $1^{\text {st }}$ January 2007 to $30^{\text {th }}$ December 2007. When the physical condition is improved, and after establishing rapport with the patient, the information was collected using suicide intent scale first designed by Beck ${ }^{1}$ and a self designed semi-structured performa. The diagnosis of suicidal attempt and associated mental disorders was made according to ICD-10 $0^{12}$. All the collected data was entered in the computer statistical software SPSS 10.0 for windows. Appropriate statistical tests were used for analyzing the data.

\section{Results}

Total numbers of patients were 43. Table 1 depicts the Suicide Intent Scale scores of the subjects who attempted suicide. The result had shown that the majority of cases were female $69.8 \%(n=30)$ and male were $30.2 \%(n=13)$. $58.1 \%(n=25)$ subjects had moderate suicide intent, in

\footnotetext{
Correspondence

Dr. Sudarshan N. Pradhan,

Assistant Professor, Department of Psychiatry,

Kathmandu Medical College Teaching Hospital

E-mail: drsudar@yahoo.com
} 
which $72 \%(n=18)$ were females and $28 \%(n=7)$ were males. $27.9 \%(\mathrm{n}=12)$ subjects had mild suicide intent, in which $75 \%(n=9)$ were females and $25 \%(n=3)$ males. $14 \%(n=6)$ subjects had severe suicide intent, in which $50 \%(n=3)$ were males and female each.

Table 2 shows the distribution between method of suicide attempt and suicide intent. The commonest mode of suicide was poisoning $83.7 \%(n=36)$ in which moderate suicide intent were $58.3 \%(n=21)$ followed by mild suicide intent $33.3 \%(\mathrm{n}=12)$ and severe suicide intent $8.3 \%(n=3)$.

The second commonest mode became the others, which included jumping from height and drowning, 7.0\% $(n=3)$ followed by hanging and self-injury $4.7 \%(n=2)$ each.

Severe suicide intent was seen in jumping and drowning $66.7 \%(n=2)$ and moderate suicide intent being $33.3 \%$ $(\mathrm{n}=1)$.

Table 3 shows the distribution of mode of poisoning and severity of suicide intention. The organophosphorus was the commonest method of poisoning $44.4 \%(n=16)$ followed by drugs used $33.3 \%(n=12)$. Drugs used were paracetamol, Nimsulide, Amitriptyline, Risperidone, Lorazepam, Alprazolam etc. Insecticides use were seen $16.7 \%(n=6)$ followed by others (Harpic, unknown materials) $5.6 \%(\mathrm{n}=2)$.
Among Organophosphorous poisoning moderate suicide intension was seen $56.3 \%(n=9)$ followed by mild suicide intent $31.3 \%(\mathrm{n}=5)$ and severe suicide intent $12.5 \%(\mathrm{n}=2)$.

Among drugs moderate suicide intention was 50\% $(n=6)$, followed by mild suicide intention $41.7 \%(n=5)$ and severe suicide intent $8.3 \%(n=1)$.

Table 4 shows the distribution of psychiatric diagnosis and severity of suicidal intention. The commonest diagnosis was Depressive episode $62.9 \% \quad(n=27)$, in which moderate suicide intent was $70.4 \%(n=19)$ followed by mild suicide intent $14.8 \%(n=4)$ and severe suicide intent $14.8 \%(n=4)$.

Then second most common diagnosis became Adjustment Disorder $11.6 \% \quad(n=5)$, in which mild suicide intent was $60 \%(n=3)$ and moderate suicide intent $40 \%(n=2)$.

Schizophrenia and impulsive was the $3^{\text {rd }}$ most common diagnosis, 9.3\% $(n=4)$. Among schizophrenia patients moderate suicide intention was $75 \%(n=3)$ and severe suicide intention was $25 \%(\mathrm{n}=1)$. Among impulsive act all cases were seen mild suicide intention. Among bipolar affective disorder each one patient fell in moderate and severe suicide intent category.

Table 1: Sex Distribution

\begin{tabular}{|c|c|c|c|c|c|}
\hline \multicolumn{2}{|c|}{} & \multicolumn{3}{|c|}{ Suicide Intent Scale } & Total \\
\cline { 3 - 6 } \multicolumn{2}{|c|}{ Sex } & Mild & Moderate & Severe & \\
\cline { 2 - 6 } & Female & $3(7.0 \%)$ & $7(16.3 \%)$ & $3(7.0 \%)$ & $13(30.2 \%)$ \\
\hline Total & $9(20.9 \%)$ & $18(41.9 \%)$ & $3(7.0 \%)$ & $30(69.8 \%)$ \\
\hline
\end{tabular}

Mean Beck SIS: 13.88

Table 2: Methods of Suicide attempts

\begin{tabular}{|c|c|c|c|c|c|}
\hline \multirow{2}{*}{} & \multicolumn{4}{|c|}{ Suicide Intent Scale } & \multirow{2}{*}{ Total } \\
\cline { 3 - 6 } & & $\begin{array}{c}\text { Mild } \\
\text { Depression }\end{array}$ & $\begin{array}{c}\text { Moderate } \\
\text { Depression }\end{array}$ & $\begin{array}{c}\text { Severe } \\
\text { Depression }\end{array}$ & $2(4.7 \%)$ \\
\hline \multirow{3}{*}{$\begin{array}{c}\text { Method } \\
\text { of Suicide } \\
\text { attempt }\end{array}$} & Hanging & - & $2(4.7 \%)$ & - & $36(83.7 \%)$ \\
\cline { 2 - 6 } & Poisoning & $12(27.9 \%)$ & $21(48.8 \%)$ & $3(7.0 \%)$ & $2(4.7 \%)$ \\
\cline { 2 - 6 } & Self Injury & - & $1(2.3 \%)$ & $1(2.3 \%)$ & $15(28.3 \%)$ \\
\hline Total & $\begin{array}{c}\text { Others (Jumping } \\
\text { Drowning) }\end{array}$ & - & $1(2.3 \%)$ & $2(4.7 \%)$ & $43(100 \%)$ \\
\hline P-value & & $12(27.9 \%)$ & $25(58.1 \%)$ & $6(14.0 \%)$ & \\
\hline
\end{tabular}


Table 3: Poisoning

\begin{tabular}{|l|c|c|c|c|c|}
\hline \multicolumn{2}{|c|}{} & \multicolumn{3}{|c|}{ Suicide Intent Scale } & \multirow{2}{*}{ Total } \\
\cline { 3 - 6 } \multicolumn{2}{|c|}{} & $\begin{array}{c}\text { Mild } \\
\text { Depression }\end{array}$ & $\begin{array}{c}\text { Moderate } \\
\text { Depression }\end{array}$ & $\begin{array}{c}\text { Severe } \\
\text { Depression }\end{array}$ & \\
\hline \multirow{4}{*}{ Poisoning } & Drugs & $5(13.9 \%)$ & $6(16.7 \%)$ & $1(2.8 \%)$ & $12(33.3 \%)$ \\
\cline { 2 - 6 } & Insecticides & $1(2.8 \%)$ & $5(13.9 \%)$ & - & $6(16.7 \%)$ \\
\cline { 2 - 6 } & Organophosphorous & $5(13.9 \%)$ & $9(25.0 \%)$ & $2(5.6 \%)$ & $16(44.4 \%)$ \\
\cline { 2 - 6 } & Others (Harpic unknown) & $1(2.8 \%)$ & $1(2.8 \%)$ & - & $2(5.6 \%)$ \\
\hline Total & $12(33.3 \%)$ & $21(58.3 \%)$ & $3(8.3 \%)$ & $36(100 \%)$ \\
\hline P-value & \multicolumn{4}{|c|}{0.267} \\
\hline
\end{tabular}

Table 4: Diagnosis

\begin{tabular}{|l|c|c|c|c|c|}
\hline \multirow{2}{*}{} & \multicolumn{3}{|c|}{ Suicide Intent Scale } & \multirow{2}{*}{ Total } \\
\cline { 3 - 6 } \multicolumn{2}{c|}{} & $\begin{array}{c}\text { Mild } \\
\text { Depression }\end{array}$ & $\begin{array}{c}\text { Moderate } \\
\text { Depression }\end{array}$ & $\begin{array}{c}\text { Severe } \\
\text { Depression }\end{array}$ & \\
\hline \multirow{4}{*}{ Diagnosis } & Depressive episode & $4(9.3 \%)$ & $19(44.2 \%)$ & $4(9.3 \%)$ & $27(62.8 \%)$ \\
\cline { 2 - 6 } & Schizophrenia & - & $3(7.0 \%)$ & $1(2.3 \%)$ & $4(9.3 \%)$ \\
\cline { 2 - 6 } & Conversion Disorder & $1(2.3 \%)$ & - & - & $1(2.3 \%)$ \\
\cline { 2 - 6 } & Adjustment Disorder & $3(7.0 \%)$ & $2(4.7 \%)$ & - & $5(11.6 \%)$ \\
\cline { 2 - 6 } & Bipolar Affective Disorder & - & $1(2.3 \%)$ & $1(2.3 \%)$ & $2(4.7 \%)$ \\
\cline { 2 - 6 } & Impulsive act & $4(9.3 \%)$ & - & - & $4(9.3 \%)$ \\
\hline Total & & $12(27.9 \%)$ & $25(58.1 \%)$ & $6(14.0 \%)$ & $43(100 \%)$ \\
\hline P-value & & \multicolumn{3}{|c|}{0.002} \\
\hline
\end{tabular}

\section{Discussion}

The present study showed that $58.1 \%$ of cases had moderate suicidal intent, which is consistent with the study of $\mathrm{Kumar}^{6}$ which reported that $49.0 \%$ of cases had moderate suicidal intent. The current study demonstrated that those suicide attempters with higher suicidal intent resembled suicide in personal and clinical characteristics as well as in the manner of carrying out the suicidal act. The current study had shown that the Beck's mean SIS is 13.88. In the study conducted by Ferriena $^{7}$, the Beck's mean SIS scores were significantly higher for the parasuicide group, which was found to be 18.32 , comparable to the non-parasuicidal group.

The severity of suicide intention in Schizophrenia was found to be lesser in comparison to depression. However, it is seen that suicide intension was mild in the patients with impulsive act. However, it is seen that schizophrenics attempt suicide due to the influence of commanding hallucinations or external forces, which shows that their intention was not killing themselves, rather following the instructions. It is important to notice that schizophrenic patient's suicidal behavior also indicate the associated depression, suicidal intent, worthlessness and hopelessness etc.
The current study depicts that the intention of suicide is quite higher in the poisoning mode of suicidal attempt. It indicates that those adopting this mode have high suicide intention. In the hanging mode of suicide attempt also the severity of suicide intention is quite high (8).

Organophosphorous Poisoning was the most frequent method employed for attempting suicide in our sample. This has been repeatedly confirmed by many studies done in India ${ }^{6,9}$ and Nepal ${ }^{10,11}$. In our study, severity of suicide was higher in patients consuming organophosphorous compounds. This showed that individuals, who had intense desire to kill themselves, would easily find such substance and factors like feasibility, accessibility, credibility and rapidity of action could be behind the choice of the method for attempting suicide.

\section{Conclusion}

The prevalence of psychiatric disorders in suicide attempters necessitates greater awareness of suicidal risk and early intervention as a preventive strategy. The increasing problem of organophosphorous poisoning and drug overdose demands strict legal scrutiny in the availability of common means of attempting suicide. 


\section{References}

1. Beck AT. Scuyler D. Herman I: Development of Suicidal Intent Scales. In the Prediction of Suicide Edited by: Beck AT, Resnick HLP. Lottieri DJ. Bowie, Maryland: Charles Press; 1974: 45-56.

2. Nordentoft M, Breum L, Munck LK, Nordestgaarel AG, Hunding A, Bjaeldager PAL: High mortality by natural ands unnatural causes; a 10 year follow up study of patients admitted to a poisoning treatment centre after suicide attempts, BMJ 1993, 306:1637-1641.

3. Hawton K. Fagg J: Suicide, and other causes of death, following attempted suicide. Br. J. Psychiatry 1988, 152: 359-366.

4. Suokas J, Suominen K, Isometsa E, Ostamo A, Lonnqvist J: Long-term risk factors for suicide mortality after attempted suicide- findings of a 14 year follow up study. Acta psych Scand 2001. 104:117-121.

5. Bertolote, J.M., Guidelines for the Primary Prevention of Mental, Neurological and Psychosocial Disorders, IV. Suicide, Geneva. World Health Organization 1993.

6. Kumar PN.S. Age and Gender Related Analysis of Psychosocial Factors in Attempted suicide, 1998, Indian Journal of Psychiatry, 40 (4), 338345 .
7. Ferriera da Casto, E. Cunha, M. A. Pimenta, C. Parasuicide and Mental Disorders. 1998 Acta Psych Scand, 97, 25-31.

8. Pradhan S.N., Rajbhandari K.C., Sharma V.D., Khalid A., Koirala N.R., Ojha S.P., Pokharel A., Sharma S.C., Rana M.. A study of mode of attempted suicide 2001; 2(4), 100-107.

9. Galgali R.B., Rao S.M.V., Appaya A.P. \& Srinivasan K. Psychiatric diagnosis of self poisoning cases. A General Hospital Study, 1998. Indian Journal of Psychiatry, 40 (3), 254259.

10. Prasad P.N. \& Karki P. Poisoning cases of TUTH Emergency, a one year review, 1997. Journal of Institute of Medicine 19, 18-24.

11. Kafle K.K., Gyawali K.K. Organophosphorus Commonest Poisoning Agent 1992. Journal of Institute of Medicine 14, 228-233.

12. World Health Organization. The ICD-10 Classification of Mental and Behavioral Disorders: Diagnostic Criteria for Research; 1993; WHO 